\title{
Evaluation of the Effects of Deep Brain Stimulation of the Subthalamic Nucleus and Levodopa Treatment on Parkinsonian Voice Using Perturbation, Nonlinear Dynamic, and Perceptual Analysis
}

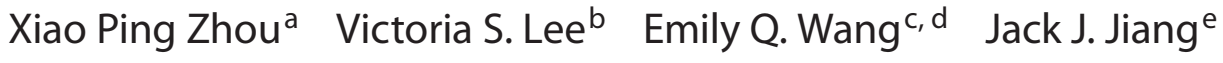 \\ ${ }^{a}$ Department of Neurosurgery, Shanghai Second Military Medical University, Shanghai, China; ${ }^{b}$ Department \\ of Surgery, Division of Otolaryngology, University of Wisconsin-Madison, Madison, Wisc., and ' ${ }^{\mathrm{D}}$ Department of \\ Communication Disorders and Sciences and ${ }^{\mathrm{d}}$ Department of Otolaryngology and Bronchoesophagology, \\ Rush University Medical Center, Chicago, III., USA; ${ }^{\mathrm{e} D e p a r t m e n t ~ o f ~ O t o l a r y n g o l o g y, ~ S h a n g h a i ~ E E N T ~ H o s p i t a l, ~}$ \\ Fudan University Medical School, Shanghai, China
}

\section{Key Words}

Parkinson's disease • Voice analysis • Perturbation analysis • Nonlinear dynamics - Perceptual analysis - Deep brain stimulation · Subthalamic nucleus · Levodopa

\begin{abstract}
Background/Aims: To quantify aperiodic phonation, nonlinear dynamic methods of acoustic voice analysis, such as correlation dimension, have been shown to be useful. The purpose of this study is to evaluate the validity of nonlinear dynamic analysis as a voice analysis tool for the effects of deep brain stimulation (DBS) and levodopa on patients with Parkinson's disease (PD). Methods: In this study, the effects of DBS and levodopa treatment on patients with PD were measured using perturbation, nonlinear dynamic, and perceptual analysis. Nineteen PD patients that received bilateral $(n=9)$, left $(n=7)$, or right $(n=3)$ DBS performed sustained vowel phonations, which were recorded before and after medication with the stimulator off and on. Recordings were also taken of 10 PD patients who did not receive DBS surgery before and after medication to provide a baseline. Results: A mixed two-way ANOVA (surgery, medication) generated significant positive treatment effects of DBS only in mean log-transformed $D_{2}$, which was supported by mean
\end{abstract}

log-transformed shimmer, $\mathrm{vF}_{0}$ (variability in fundamental frequency), and vAm (peak-to-peak amplitude variation). Conclusion: These findings may indicate the validity of nonlinear dynamic analysis as a complement to perceptual analysis in clinical PD voice studies.

Copyright $\odot 2009$ S. Karger AG, Basel

\section{Introduction}

Parkinson's disease (PD) is a neurological disease that involves the degeneration of dopamine-producing cells in the substantia nigra, causing increased inhibition of the thalamus and the brainstem locomotive center [1]. PD causes both motor and vocal impairment. Impaired parkinsonian voice has been described as breathy, tremulous, high-pitched, monotone, quiet, and hoarse [2, 3].

The use of levodopa is a standard treatment for PD and has been shown to be effective in combating PD motor symptoms, although its effects on PD voice are inconsistent [4-9]. A new treatment for PD is deep brain stimulation (DBS) of the subthalamic nucleus (STN). DBS treatment involves using a unilateral or bilateral stimulator to target electrical signals to the STN, which is believed to disrupt brain signaling responsible for the motor and vo-

\section{KARGER}

Fax +4161306 1234 E-Mail karger@karger.ch www.karger.com
(C) 2009 S. Karger AG, Basel

1021-7762/09/0614-0189\$26.00/0

Accessible online at:

www.karger.com/fpl
Dr. Jack J. Jiang, Adjunct Professo

Fudan University Medical School

83 Fen Yang Road

Shanghai 200031 (PR China)

Tel. +1 608265 7888, Fax +1 608265 2139, E-Mail jackjjiang@gmail.com 
cal impairment symptoms of PD $[1,10,11]$. DBS has been shown to alleviate motor symptoms, but its effects on voice are less clear [12-14]. Recent studies focusing on the use of levodopa in conjunction with DBS of the STN have argued that DBS of the STN affects neuronal structures involved in voice that are not affected by levodopa, namely nondopaminergic lesions [15-17]. As a result, the administration of levodopa in conjunction with DBS of the STN is thought to have a greater effect on PD vocal impairment than the use of levodopa alone $[5,16]$. These studies have applied acoustic perturbation analysis to evaluate the effects of DBS and levodopa $[11,18,19]$.

Perturbation analysis, however, requires near periodicity in order to reliably extract a pitch from voice samples. Correlation dimension, produced from nonlinear dynamic analysis, can quantify aperiodic voice commonly found in PD patients. Increased correlation dimension may indicate worsening of hoarseness, which perceptually characterizes aperiodic voice [20-25]. In addition, nonlinear vocal fold models are able to capture the pathologic characteristics of PD voice, including reduced vibratory amplitude, incomplete vocal fold closure, increased phonation threshold pressure, vocal tremor, subharmonics, and vocal irregularity [26]. Thus, nonlinear dynamic analysis may be a useful clinical tool for PD voice analysis.

The purpose of this study is to investigate the usefulness of nonlinear dynamic analysis to evaluate the effects of unilateral and bilateral DBS of the STN in conjunction with levodopa on $P D$ voice. $P D$ voices of surgical patients are evaluated in the before-medication stimulator-off (BMSOFF), before-medication stimulator-on (BMSON), after-medication stimulator-off (AMSOFF), and aftermedication stimulator-on (AMSON) situations. The results for surgical patients are compared to those for nonsurgical patients in the before-medication (BM) and after-medication (AM) situations.

\section{Materials and Methods}

\section{Participants}

The Committee of Ethics at Shanghai Second Military Medical University Hospital approved the protocol and consent procedure used in this study. An attending neurologist recruited 19 patients diagnosed with idiopathic PD, 11 males and 8 females with an average age of 63.8 years, to undergo DBS-STN surgery (table 1). The details of the surgery have been discussed elsewhere [27]. Nine patients had bilateral, 7 had left, and 3 had right electrode placement. The decision to undergo DBS surgery was made by the subjects as part of their clinical care independent from the interests of this study. Ten patients diagnosed with idiopathic PD,
6 females and 4 males with a mean age of 66.8 years, who did not undergo surgery were also selected (table 2). None of the participants suffered from vocal deficits caused by diseases other than PD, symptoms outside of those common to PD as detected by laryngeal endoscopy, cognitive hearing impairment, or depression. The attending neurologist selected patients based on consistency in the criteria listed in tables 1 and 2 .

\section{Double-Blindness}

The attending neurologist recruited patients. Two research assistants collected the vocal recordings, one controlling the stimulator and administering the medication and another, blinded to the stimulator and medication conditions, directing the patient to perform sustained phonations. The patient was blinded to the stimulator condition but not to the medication condition. Therefore, double-blindness was satisfied with respect to DBS treatment. Blindness of the research assistant was achieved with respect to medication. Another research assistant, unaware of the stimulator or medication conditions, conducted the data analysis, achieving blindness at this stage of data processing with respect to both treatment factors.

\section{Recording Procedure}

For patients who received DBS, 2 doctors conducted the recordings in the 4 situations, BMSOFF, BMSON, AMSOFF, and AMSON. Recordings were taken before medication (no medication for $12 \mathrm{~h}$ ) and after medication (medication for $1 \mathrm{~h}$ ) with the stimulator off (stimulator deactivated for $30 \mathrm{~min}$ ) and the stimulator on (stimulator activated for at least $12 \mathrm{~h}$ ). For patients who did not undergo surgery, recordings were taken in the BM (no medication for $12 \mathrm{~h}$ ) and AM (medication for $1 \mathrm{~h}$ ) situations. The smallest amount of medication was administered to achieve the best results and least side effects (tables 1,2). At each time period, sustained /a/ vowel phonations of no less than $5 \mathrm{~s}$ were recorded in a sound-attenuated room using a head-mounted microphone (AKG Acoustics, Vienna, Austria) positioned at $15 \mathrm{~cm}$ from the mouth at a 45-degree angle. Audio files were recorded using Multispeech software (KayPENTAX, Lincoln Park, N.J., USA) at a sampling rate of $25 \mathrm{kHz}$. The patients were asked to perform the sustained vowel phonations at their habitual loudness and pitch. For each patient, 5 replicate recordings in each of the situations were taken, and 3 replicates were randomly selected for vocal analysis. One-second segments were cut from the middle of these sustained voices, eliminating the offset and onset of phonation. These segments were processed using nonlinear dynamic, perturbation, and perceptual analysis.

\section{Perturbation Analysis}

The 3 one-second segments of sustained phonations were analyzed using CSpeech 4.0 software (Paul Milenkovic, Madison, Wisc., USA). Percent jitter, percent shimmer, and signal-to-noise ratio (SNR) values were obtained for all vocal segments. The Multi-Dimensional Voice Program, model 5105, version 2.0 (Kay Elemetrics Corporation), was used to obtain the perturbation measures of $\mathrm{vF}_{0}$ (variability in fundamental frequency) and $\mathrm{vAm}$ (peak-to-peak amplitude variation).

CSpeech was also used to calculate err, which is a measure of the number of times the algorithm failed to extract a pitch period [28]. An err greater than 10 indicated an unreliable pitch period. The waveforms of samples with err values greater than 10 had 
Table 1. Characteristics of patients who received DBS

\begin{tabular}{|c|c|c|c|c|c|c|c|c|}
\hline $\begin{array}{l}\text { Patient } \\
\text { no. }\end{array}$ & Gender & Age & $\begin{array}{l}\text { Side } \\
\text { of } \\
\text { STN }\end{array}$ & $\begin{array}{l}\text { Hoehn- } \\
\text { Yahr score }\end{array}$ & $\begin{array}{l}\text { UPDRS-III } \\
\text { score }\end{array}$ & $\begin{array}{l}\text { UPDRS-III } \\
\text { item } 18 \\
\text { (speech) score }\end{array}$ & $\begin{array}{l}\text { PD duration } \\
\text { since diagnosis } \\
\text { years }\end{array}$ & $\begin{array}{l}\text { Medication } \\
\text { dosage }\end{array}$ \\
\hline 1 & female & 68 & both & III & 51 & 0 & 12 & $\begin{array}{l}250 \mathrm{mg} \mathrm{M} \\
100 \mathrm{mg} \text { SCR }\end{array}$ \\
\hline 2 & female & 62 & both & III & 60 & 0 & 12 & $375 \mathrm{mg} \mathrm{M}$ \\
\hline 3 & male & 67 & both & IV & 108 & 2 & 14 & $500 \mathrm{mg}$ SCR \\
\hline 4 & male & 61 & left & III & 51 & 0 & 18 & $250 \mathrm{mg} \mathrm{M}$ \\
\hline 5 & male & 50 & both & III & 78 & 1 & 5 & $\begin{array}{l}625 \mathrm{mg} \mathrm{M} \\
400 \mathrm{mg} \text { SCR }\end{array}$ \\
\hline 6 & male & 56 & both & III & 58 & 0 & 10 & $250 \mathrm{mg} \mathrm{M}$ \\
\hline 7 & male & 65 & both & IV & 82 & 1 & 8 & $375 \mathrm{mg} \mathrm{M}$ \\
\hline 8 & female & 65 & both & III & 79 & 1 & 4 & $687.5 \mathrm{mg} \mathrm{M}$ \\
\hline 9 & female & 57 & left & $\mathrm{V}$ & 100 & 2 & 11 & $\begin{array}{l}375 \mathrm{mg} \mathrm{M} \\
200 \mathrm{mg} \mathrm{SCR} \\
750 \mathrm{mg} \mathrm{C}\end{array}$ \\
\hline 10 & male & 72 & left & III & 67 & 1 & 6 & $\begin{array}{l}750 \mathrm{mg} \mathrm{M} \\
500 \mathrm{mg} \mathrm{C}\end{array}$ \\
\hline 11 & male & 76 & left & III & 80 & 1 & 13 & $250 \mathrm{mg} \mathrm{M}$ \\
\hline 12 & male & 63 & left & III & 62 & 1 & 8 & $\begin{array}{l}250 \mathrm{mg} \mathrm{M} \\
100 \mathrm{mg} \mathrm{SCR}\end{array}$ \\
\hline 13 & male & 58 & left & IV & 84 & 1 & 10 & $250 \mathrm{mg} \mathrm{M}$ \\
\hline 14 & male & 77 & both & III & 65 & 1 & 7 & $\begin{array}{l}500 \mathrm{mg} \mathrm{M} \\
100 \mathrm{mg} \mathrm{SCR}\end{array}$ \\
\hline 15 & female & 48 & left & III & 62 & 0 & 10 & $500 \mathrm{mg} \mathrm{M}$ \\
\hline 16 & female & 66 & right & III & 65 & 0 & 7 & $750 \mathrm{mg} \mathrm{M}$ \\
\hline 17 & female & 65 & right & III & 65 & 0 & 6 & $562.5 \mathrm{mg} \mathrm{M}$ \\
\hline 18 & female & 68 & both & IV & 78 & 1 & 10 & $750 \mathrm{mg} \mathrm{M}$ \\
\hline 19 & male & 69 & right & III & 62 & 1 & 6 & $100 \mathrm{mg} \mathrm{T}$ \\
\hline Mean & $\mathrm{N} / \mathrm{A}$ & 63.8 & N/A & $\begin{array}{l}3.3(\mathrm{III}=3, \\
\mathrm{IV}=4, \mathrm{~V}=5)\end{array}$ & 71.4 & 0.7 & 9.3 & N/A \\
\hline
\end{tabular}

M = Madopar; $\mathrm{T}$ = Trastal; SCR = Sinernet CR; C = Celance. Hoehn-Yahr and UPDRS-III scores were recorded before the patients underwent surgery and without medication. As a result of lack of regular health care, a few patients have very short disease durations that are inconsistent with the stage of PD because of late diagnosis or diagnosis at the time of the study.

type 2 (bifurcations and modulations evident) or type 3 (aperiodic and chaotic) signals. Studies have determined that perturbation analysis is only reliable for nearly periodic voice samples. Thus, percent jitter, percent shimmer, $\mathrm{SNR}, \mathrm{vF}_{0}$, and vAm values for these samples were eliminated [29].

\section{Nonlinear Dynamic Analysis}

Nonlinearity in human voice production is related to the machinery of the human voice [22]. Correlation dimension, produced from nonlinear dynamic analysis, gives a quantitative estimate of the number of degrees of freedom needed to describe the dynamic system [30]. Higher dimensionality of $\mathrm{D}_{2}$ indicates a more complex system and a higher degree of vocal pathology [21-
25]. The theory and usage of nonlinear dynamic methods has been discussed in previous literature [22, 24, 30, 31-35]. Correlation dimension calculations were determined based on past research of excised larynx phonations and live human voices $[21,25$, 33-35]. Figure 1 shows phonatory time series

$$
\begin{aligned}
& x\left(t_{i}\right), t_{i}=t_{0}+i \Delta t,(i=1,2, \ldots, N) \\
& \Delta t=1 / f_{s}(\mathrm{~N}=25,000)
\end{aligned}
$$

from a PD patient that received DBS in the BMSON situation. Vocal segments were analyzed over a period of $1 \mathrm{~s}$ (figures were magnified). Figure 2 shows the phase space reconstruction $[x(t), x(t+$ $\tau)$ ] with $\tau$ as the time delay calculated by the Fraser and Swinney 
Table 2. Characteristics of nonsurgical patients

\begin{tabular}{|c|c|c|c|c|c|c|c|}
\hline $\begin{array}{l}\text { Patient } \\
\text { no. }\end{array}$ & Gender & Age & $\begin{array}{l}\text { Hoehn- } \\
\text { Yahr score }\end{array}$ & $\begin{array}{l}\text { UPDRS-III } \\
\text { score }\end{array}$ & $\begin{array}{l}\text { UPDRS-III } \\
\text { item } 18 \\
\text { (speech) score }\end{array}$ & $\begin{array}{l}\text { PD duration } \\
\text { since diagnosis } \\
\text { years }\end{array}$ & $\begin{array}{l}\text { Medication } \\
\text { dosage }\end{array}$ \\
\hline 1 & female & 74 & III & 88 & 1 & 2 & $\begin{array}{l}500 \mathrm{mg} \mathrm{T} \\
300 \mathrm{mg} \mathrm{SCR}\end{array}$ \\
\hline 2 & female & 74 & IV & 100 & 2 & 5 & $375 \mathrm{mg} \mathrm{M}$ \\
\hline 3 & female & 73 & III & 76 & 1 & 3 & $375 \mathrm{mg} \mathrm{M}$ \\
\hline 4 & female & 59 & IV & 94 & 1 & 7 & $\begin{array}{c}812.5 \mathrm{mg} \mathrm{M} \\
100 \mathrm{mg} \mathrm{T}\end{array}$ \\
\hline 5 & female & 57 & III & 64 & 0 & 6 & $\begin{array}{r}812.5 \mathrm{mg} \mathrm{M} \\
0.1375 \mathrm{mg} \mathrm{C} \\
2.5 \mathrm{mg} \mathrm{A}\end{array}$ \\
\hline 6 & female & 77 & III & 68 & 0 & $<1$ & $375 \mathrm{mg} \mathrm{M}$ \\
\hline 7 & male & 61 & IV & 96 & 1 & 9 & $\begin{array}{l}750 \mathrm{mg} \mathrm{M} \\
100 \mathrm{mg} \mathrm{T}\end{array}$ \\
\hline 8 & male & 68 & III & 72 & 1 & 4 & $\begin{array}{c}750 \mathrm{mg} \mathrm{M} \\
50 \mathrm{mg} \mathrm{T}\end{array}$ \\
\hline 9 & male & 49 & III & 62 & 0 & 2 & $750 \mathrm{mg} \mathrm{M}$ \\
\hline 10 & male & 76 & IV & 86 & 2 & 4 & $\begin{array}{l}500 \mathrm{mg} \mathrm{M} \\
100 \mathrm{mg} \mathrm{T}\end{array}$ \\
\hline Mean & N/A & 66.8 & $\begin{array}{l}3.4(\mathrm{III}=3 \\
\mathrm{IV}=4, \mathrm{~V}=5)\end{array}$ & 80.6 & 0.9 & 4.2 & $\mathrm{~N} / \mathrm{A}$ \\
\hline
\end{tabular}

M = Madopar; $\mathrm{T}$ = Trastal; SCR = Sinernet CR; C = Celance; A = Artane. Hoehn-Yahr and UPDRS-III scores were recorded without medication. As a result of lack of regular health care, a few patients have very short disease durations that are inconsistent with the stage of PD because of late diagnosis or diagnosis at the time of the study.

mutual information method (1986). The reconstructed phase space maps the vocal fold vibrations as a function of time, qualitatively showing the dynamic behavior of a signal. Periodic and aperiodic signals produce closed and irregular trajectories, respectively. In the Grassberger and Procaccia [30] correlation dimension (1983),

$$
\begin{aligned}
& D_{2}=\lim _{r \rightarrow 0} \frac{\log C(r)}{\log r} \\
& C(W, N, r)= \\
& \frac{2}{(N+1-W)(N-W)} \sum_{n=W}^{N-1} \sum_{i=0}^{N-1-n} \theta\left(r-\left\|\mathbf{X}_{i}-\mathbf{X}_{i+n}\right\|\right)
\end{aligned}
$$

where $r$ is the radius around $\mathbf{X}_{i}$ and $\mathrm{C}$ is calculated using Theiler's formula (1986). $W$ is the time delay $\tau$ and

$$
\theta(x)= \begin{cases}1 & x>0 \\ 1 & x \leq 0\end{cases}
$$

$\mathrm{D}_{2}$ versus $r$ is fit with a linear curve in the scaling region. As the embedding dimension $m$ is increased, the slopes of these two curves converge. Figure 3 shows the $\mathrm{D}_{2}$ versus $r$ curves from the same $\mathrm{PD}$ voice. The slopes of the $\mathrm{D}_{2}$ versus $r$ curves approach $3.038 \pm 0.004$ in the scaling region, which is the estimated $\mathrm{D}_{2}$ of this voice. Using the steps outlined above, the estimated $\mathrm{D}_{2}$ values of the waveforms were obtained.

\section{Perceptual Analysis}

A perceptual rating of general vocal impairment was obtained for all vocal segments to preliminarily investigate the relationship between the $\mathrm{D}_{2}$ and perceptual measures. The 1-second segments were rated for general vocal impairment by 1 graduate student with 6 years of voice research and perceptual analysis experience. One undergraduate student with 2 years of voice research experience analyzed $10 \%$ of the vocal segments to check for interrater reliability. These raters spent over $5 \mathrm{~h}$ of training for perceptual analysis with Sound Judgment software (Finders University, Adelaide, Australia) and with other clinical experiments involving perceptual analysis, maximizing the accuracy of their perceptual judgments. Neither rater had a history of hearing or communication difficulties. The voice segments were presented in randomized order to each rater through headphones (Targus Inc., Anaheim, Calif., USA) in a quiet isolated room. The raters were asked to give scores of general vocal impairment on a scale from 0 to 6 $(0=$ none, $6=$ severe $)$. In this study, the raters had high interrater 


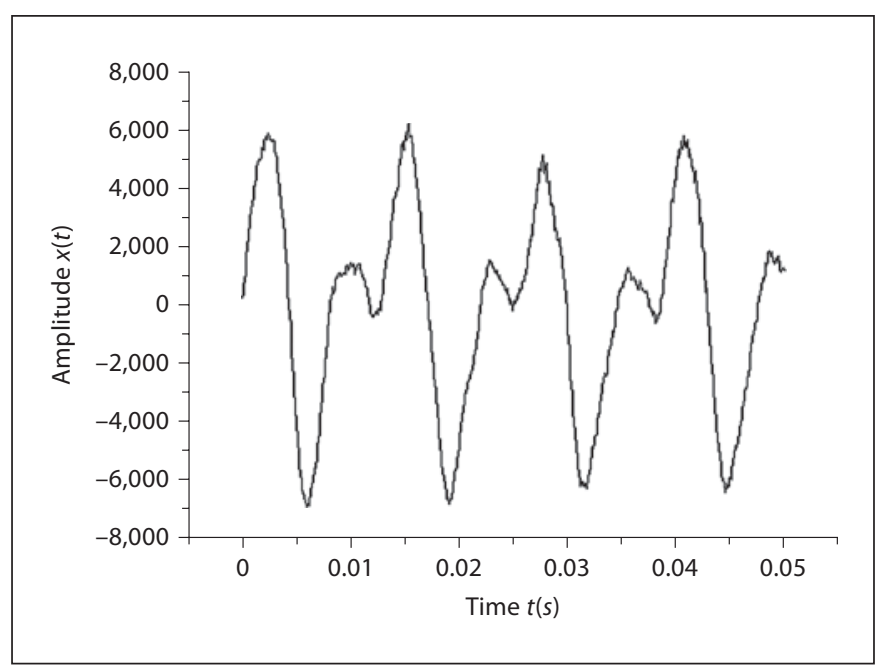

Fig. 1. Parkinsonian voice acoustic waveform of a patient that received DBS in the BMSON situation.

agreement, with a Spearman's rank order correlation coefficient of 0.972 and $p<0.0001$. Because of the availability of only 2 experienced raters, the perceptual ratings were not statistically analyzed.

\section{Statistical Analysis}

The log-transformed means for each of the voice measures $\left(D_{2}\right.$, percent jitter, percent shimmer, $\mathrm{SNR}, \mathrm{vF}_{0}, \mathrm{vAm}$ ) were calculated, since the log transformation was found to better meet the assumptions of ANOVA. For each of the 6 measures, a mixed two-way ANOVA model was fit, with fixed effects for surgery and medication and their interaction, and a random effect for trial nested within the patient, the experimental unit. Six tests were run, once with the stimulator-off and once with the stimulator-on conditions for bilateral, left, and right subsets of the surgical group. Each test carried out 3 comparisons on the fixed effects: a comparison of the no surgery and surgery conditions (BM and AM vs. BMSOFF/BMSON and AMSOFF/AMSON), a comparison of the before- and after-medication conditions (BM and BMSOFF/ BMSON vs. AM and AMSOFF/AMSON), and an interaction of the no surgery/surgery and before/after-medication conditions. If the interaction term was statistically significant, multiple comparisons were carried out using a Fisher's LSD test. In all, $36 \mathrm{ANO}$ VAs were run [ 6 measures $\times 3$ subgroups (bilateral, left, right) $\times$ 2 conditions (stimulator off or on)]. Two-sided $p$ values less than 0.05 were considered significant. Statistical computations were run on SAS 9.1 (SAS Institute, Cary, N.C., USA).

Statistical comparisons of the OFF and ON situations were not reported. Previous studies have shown that the stimulator must be turned off for a minimum of $12 \mathrm{~h}$ in order to ensure no effect [36]. In our initial study without the medication treatment factor, there was no significant difference between the OFF and ON situations. As a result, this comparison was eliminated to simplify the statistical analysis.

Analyzing Treatment Effects on Parkinsonian Voice

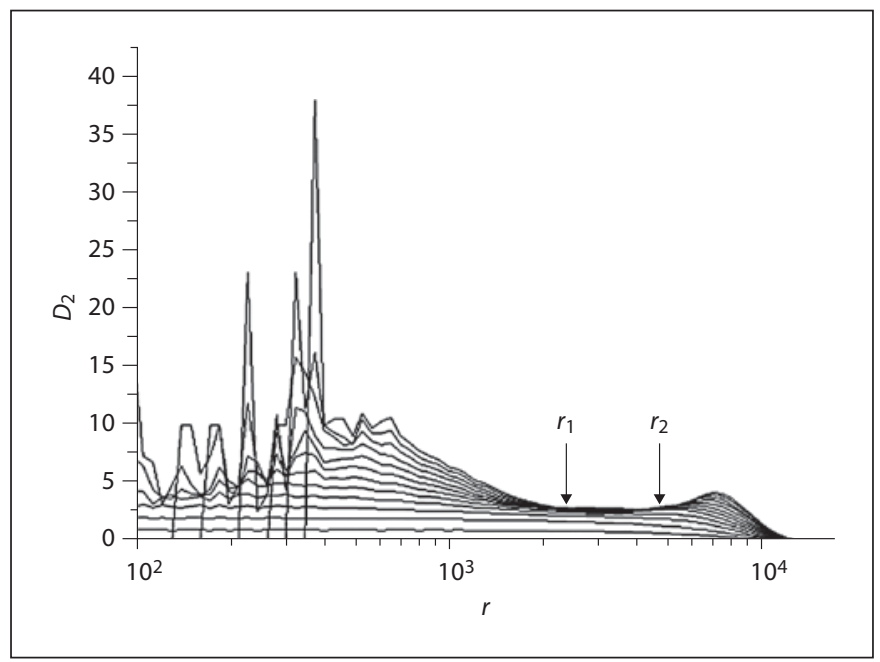

Fig. 3. The estimated $D_{2}$ value versus $r$. The curves from bottom to top correspond to the embedding dimension $\mathrm{m}=1,2,3, \ldots$, 10 .

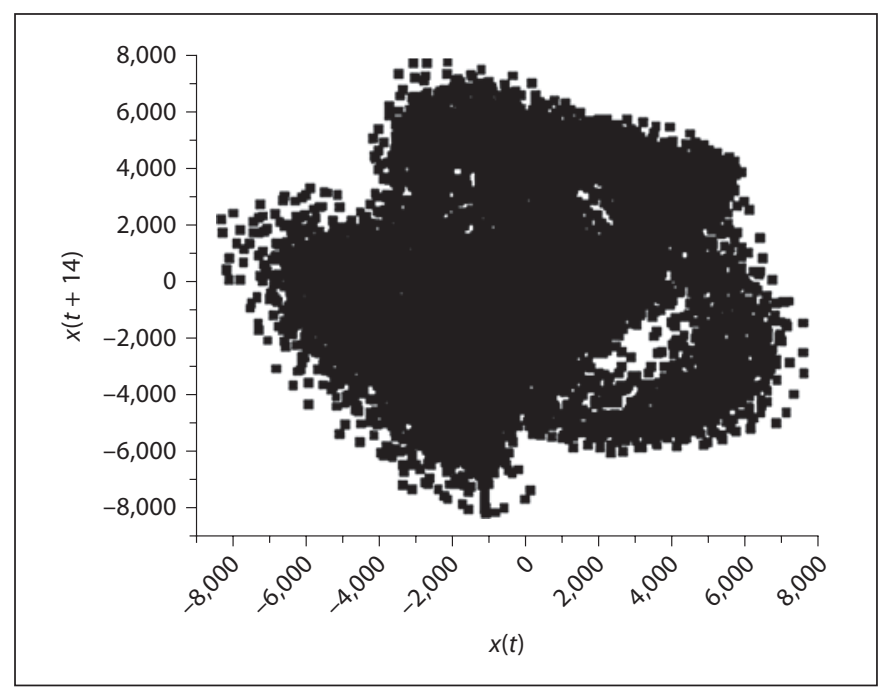

Fig. 2. The reconstructed phase space of a parkinsonian voice in this study.

\section{Results}

Table 3 shows log-transformed (indicated by 'l') mean $\mathrm{D}_{2}$, percent jitter, percent shimmer, $\mathrm{SNR}, \mathrm{vF}_{0}$, and $\mathrm{vAm}$ values for control patients in the BM and AM situations and bilateral, left, and right DBS patients in the BMSOFF, BMSON, AMSOFF, and AMSON situations. Table 4a displays the results of the mixed two-way ANOVAs. Ta- 
Table 3. Log-transformed values for DBS and nonsurgical patients for the stimulator-on and stimulator-off conditions

\begin{tabular}{|c|c|c|c|c|}
\hline & BMSOFF & BMSON & AMSOFF & AMSON \\
\hline \multicolumn{5}{|c|}{ Bilateral DBS patients $(n=9)$} \\
\hline $\log \mathrm{D}_{2}$ & $1.011 \pm 0.325$ & $0.988 \pm 0.346$ & $1.074 \pm 0.323$ & $0.994 \pm 0.354$ \\
\hline $\log \%$ jitter & $-0.997 \pm 0.768$ & $-1.019 \pm 0.656$ & $-1.110 \pm 0.590$ & $-1.182 \pm 0.523$ \\
\hline $\log \%$ shimmer & $1.402 \pm 0.589$ & $1.583 \pm 0.702$ & $1.364 \pm 0.503$ & $1.494 \pm 0.619$ \\
\hline $\log$ SNR & $2.783 \pm 0.278$ & $2.699 \pm 0.368$ & $2.816 \pm 0.231$ & $2.786 \pm 0.323$ \\
\hline $\log \mathrm{vF}_{0}$ & $0.335 \pm 0.536$ & $0.325 \pm 0.751$ & $0.207 \pm 0.769$ & $0.167 \pm 0.624$ \\
\hline $\log \mathrm{vAm}$ & $2.150 \pm 0.388$ & $2.215 \pm 1.061$ & $2.101 \pm 1.049$ & $1.576 \pm 1.635$ \\
\hline \multicolumn{5}{|c|}{ Left DBS patients $(n=7)$} \\
\hline $\log D_{2}$ & $0.817 \pm 0.238$ & $0.904 \pm 0.235$ & $0.898 \pm 0.273$ & $0.880 \pm 0.240$ \\
\hline $\log \%$ jitter & $-0.772 \pm 0.637$ & $-0.704 \pm 0.730$ & $-0.640 \pm 0.334$ & $-1.111 \pm 0.530$ \\
\hline $\log \%$ shimmer & $1.582 \pm 0.366$ & $1.792 \pm 0.635$ & $1.839 \pm 0.213$ & $1.514 \pm 0.527$ \\
\hline $\log$ SNR & $2.689 \pm 0.202$ & $2.515 \pm 0.346$ & $2.631 \pm 0.106$ & $2.710 \pm 0.284$ \\
\hline $\log \mathrm{vF}_{0}$ & $0.223 \pm 1.031$ & $0.247 \pm 0.855$ & $0.411 \pm 0.488$ & $0.372 \pm 1.151$ \\
\hline $\log \mathrm{vAm}$ & $1.153 \pm 1.825$ & $1.473 \pm 1.465$ & $1.979 \pm 0.900$ & $1.928 \pm 1.133$ \\
\hline \multicolumn{5}{|c|}{ Right DBS patients $(\mathrm{n}=3)$} \\
\hline $\log \mathrm{D}_{2}$ & $0.723 \pm 0.176$ & $0.823 \pm 0.170$ & $0.741 \pm 0.089$ & $0.786 \pm 0.241$ \\
\hline $\log \%$ jitter & $-0.501 \pm 0.635$ & $-0.506 \pm 0.434$ & $-0.533 \pm 0.431$ & $-0.619 \pm 0.428$ \\
\hline $\log \%$ shimmer & $1.635 \pm 0.399$ & $1.837 \pm 0.292$ & $1.835 \pm 0.324$ & $1.541 \pm 0.222$ \\
\hline $\log$ SNR & $2.755 \pm 0.175$ & $2.604 \pm 0.168$ & $2.649 \pm 0.113$ & $2.716 \pm 0.176$ \\
\hline $\log \mathrm{vF}_{0}$ & $0.080 \pm 0.600$ & $0.108 \pm 0.277$ & $0.125 \pm 0.555$ & $0.444 \pm 0.595$ \\
\hline \multirow[t]{2}{*}{ log vAm } & $1.675 \pm 1.446$ & $2.060 \pm 0.429$ & $1.614 \pm 1.279$ & $1.468 \pm 1.732$ \\
\hline & $\mathrm{BM}$ & & $\mathrm{AM}$ & \\
\hline \multicolumn{5}{|c|}{ Nonsurgical patients $(\mathrm{n}=10)$} \\
\hline $\log \mathrm{D}_{2}$ & $1.252 \pm 0.230$ & & $1.285 \pm 0.265$ & \\
\hline $\log \%$ jitter & $-1.064 \pm 0.532$ & & $-0.916 \pm 0.468$ & \\
\hline $\log \%$ shimmer & $1.689 \pm 0.550$ & & $1.922 \pm 0.388$ & \\
\hline $\log$ SNR & $2.671 \pm 0.365$ & & $2.587 \pm 0.214$ & \\
\hline $\log \mathrm{vF}_{0}$ & $0.870 \pm 1.436$ & & $1.400 \pm 1.480$ & \\
\hline $\log \mathrm{vAm}$ & $2.140 \pm 1.053$ & & $2.474 \pm 0.925$ & \\
\hline
\end{tabular}

Mean and standard deviation for log-transformed $\mathrm{D}_{2}$, percent jitter, percent shimmer, $\mathrm{SNR}, \mathrm{vF}$, and vAm in PD subjects in the BMSOFF and AMSOFF and BMSON and AMSON situations. Mean and standard deviation for log-transformed $\mathrm{D}_{2}$, percent jitter, percent shimmer, $\mathrm{SNR}, \mathrm{vF}_{0}$, and $\mathrm{vAm}$ for nonsurgical patients in the $\mathrm{BM}$ and $\mathrm{AM}$ situations. Perturbation values for aperiodic samples were eliminated.

ble $4 \mathrm{~b}$ displays the multiple comparisons for significant interaction terms. Figures 4 and 5 display the boxplot for $\mathrm{D}_{2}$ values and perceptual ratings, respectively, in the various patient situations.

\section{Effect of DBS (Comparison 1)}

Mean $\mathrm{lD}_{2}$ was significantly lower in bilateral, left and right DBS patients for the stimulator-off ( $\mathrm{p}=0.033, \mathrm{p}<$ $0.0001, \mathrm{p}<0.0001)$ and the stimulator-on conditions $(\mathrm{p}=$ $0.019, \mathrm{p}<0.0001, \mathrm{p}<0.0001)$ than in control patients. Figure 4 shows the significantly lower $\mathrm{D}_{2}$ values in the surgi- cal group than in the control group. Mean lshimmer was significantly lower in bilateral DBS patients for the stimulator-off conditions $(\mathrm{p}=0.036)$ than in control patients. Mean $\operatorname{lvF}_{0}$ was significantly lower in bilateral and left DBS patients for the stimulator-off ( $\mathrm{p}=0.006, \mathrm{p}=0.023)$ and the stimulator-on conditions $(\mathrm{p}=0.008, \mathrm{p}=0.043)$ than in control patients. Mean $\operatorname{lvF}_{0}$ was significantly lower in right DBS patients for the stimulator-off conditions ( $\mathrm{p}=$ $0.037)$ than in control patients. Mean lvAm was significantly lower in left and right DBS patients for the stimulator-off conditions ( $\mathrm{p}=0.035, \mathrm{p}=0.035)$. 
Table 4. Interaction of DBS and medication for the stimulator-on and stimulator-off conditions

\begin{tabular}{|c|c|c|c|c|c|c|}
\hline & \multicolumn{3}{|c|}{ Stimulator off } & \multicolumn{3}{|c|}{ Stimulator on } \\
\hline & $\begin{array}{l}\text { effect of } \\
\text { surgery }\end{array}$ & $\begin{array}{l}\text { effect of } \\
\text { medication }\end{array}$ & interaction & $\begin{array}{l}\text { effect of } \\
\text { surgery }\end{array}$ & $\begin{array}{l}\text { effect of } \\
\text { medication }\end{array}$ & interaction \\
\hline \multicolumn{7}{|l|}{ A Bilateral } \\
\hline $\log \mathrm{D}_{2}$ & $0.033^{*}$ & 0.226 & 0.690 & $0.019^{*}$ & 0.609 & 0.709 \\
\hline $\log \%$ jitter & 0.997 & 0.188 & 0.868 & 0.914 & 0.915 & 0.124 \\
\hline $\log \%$ shimmer & $0.036^{*}$ & 0.521 & 0.466 & 0.323 & 0.551 & 0.349 \\
\hline $\log$ SNR & 0.097 & 0.891 & 0.655 & 0.446 & 0.948 & 0.559 \\
\hline $\log \mathrm{vF}_{0}$ & $0.006^{*}$ & 0.394 & 0.172 & $0.008^{*}$ & 0.494 & 0.131 \\
\hline log vAm & 0.390 & 0.475 & 0.261 & 0.156 & 0.515 & $0.048^{* *}$ \\
\hline \multicolumn{7}{|l|}{ Left } \\
\hline $\log \mathrm{D}_{2}$ & $<0.0001^{*}$ & 0.253 & 0.621 & $<0.0001^{*}$ & 0.916 & 0.515 \\
\hline $\log \%$ jitter & 0.191 & 0.218 & 0.753 & 0.522 & 0.614 & $0.044^{* *}$ \\
\hline $\log \%$ shimmer & 0.372 & 0.134 & 0.832 & 0.419 & 0.908 & 0.169 \\
\hline $\log$ SNR & 0.451 & 0.750 & 0.927 & 0.963 & 0.555 & 0.340 \\
\hline $\log \mathrm{vF}_{0}$ & $0.023^{*}$ & 0.186 & 0.513 & $0.043^{*}$ & 0.256 & 0.439 \\
\hline log vAm & $0.035^{*}$ & $0.031^{*}$ & 0.307 & 0.050 & 0.155 & 0.814 \\
\hline \multicolumn{7}{|l|}{ Right } \\
\hline $\log D_{2}$ & $<0.0001^{*}$ & 0.649 & 0.898 & $<0.0001^{*}$ & 0.972 & 0.559 \\
\hline $\log \%$ jitter & 0.079 & 0.680 & 0.448 & 0.174 & 0.793 & 0.198 \\
\hline $\log \%$ shimmer & 0.734 & 0.470 & 0.780 & 0.453 & 0.751 & 0.237 \\
\hline $\log$ SNR & 0.430 & 0.695 & 0.794 & 0.645 & 0.802 & 0.688 \\
\hline $\log \mathrm{vF}_{0}$ & $0.037^{*}$ & 0.423 & 0.485 & 0.078 & 0.265 & 0.806 \\
\hline \multirow[t]{2}{*}{ log vAm } & $0.035^{*}$ & 0.662 & 0.520 & 0.104 & 0.660 & 0.117 \\
\hline & BM vs. AM & $\begin{array}{l}\text { AM vs. } \\
\text { AMSON }\end{array}$ & $\begin{array}{l}\text { AM vs. } \\
\text { BMSON }\end{array}$ & $\begin{array}{l}\text { BM vs. } \\
\text { AMSON }\end{array}$ & $\begin{array}{l}\text { BM vs. } \\
\text { BMSON }\end{array}$ & $\begin{array}{l}\text { BMSON vs. } \\
\text { AMSON }\end{array}$ \\
\hline \multirow{2}{*}{$\begin{array}{l}\text { B } \log \% \text { jitter } \\
\log \text { vAm }\end{array}$} & 0.214 & 0.929 & 0.435 & 0.670 & 0.195 & 0.107 \\
\hline & 0.281 & 0.026 & 0.345 & 0.131 & 0.848 & 0.235 \\
\hline
\end{tabular}

A shows mixed two-way ANOVA p values for log-transformed $\mathrm{D}_{2}$, percent jitter, percent shimmer, $\mathrm{SNR}, \mathrm{vF}_{0}$, and vAm. B shows Fisher's LSD p values for multiple comparisons of the two significant interaction terms (indicated by $\left.{ }^{* *}\right) .{ }^{*}$ indicates $\mathrm{p}$ values significant at the 0.05 level.

\section{Effect of Medication (Comparison 2)}

Mean lvAm was significantly lower in left DBS patients for the stimulator-off conditions $(p=0.031)$ than in control patients. No other ANOVAs for bilateral, left, or right DBS comparing the before- and after-medication conditions generated statistically significant results.

\section{Interaction of DBS and Medication (Comparison 3)}

The interaction term for mean ljitter in left DBS patients for the stimulator-on conditions was statistically significant $(\mathrm{p}=0.044)$. The interaction term for mean lvAm in bilateral DBS patients for the stimulator-on conditions was also statistically significant $(\mathrm{p}=0.048)$. None of the multiple comparisons were significant for either term.

\section{Perceptual Analysis}

In comparing the no-surgery and surgery conditions (BM and AM vs. BMSOFF/BMSON and AMSOFF/ AMSON) in figure 5, the surgery conditions have similar perceptual ratings. In comparing the before- and aftermedication conditions (BM and BMSOFF/BMSON vs. $\mathrm{AM}$ and $\mathrm{AMSOFF} / \mathrm{AMSON}$ ) in figure 5, the medication conditions also have similar perceptual ratings. The mean perceptual ratings for stimulator-on situations are lower than those of the respective stimulator-off situations for bilateral, left, and right DBS patients. 
Fig. 4. Boxplot of $\mathrm{D}_{2}$ values for nonsurgical patients in the BM and AM situations and surgical patients (bilateral, left, and right) in the BMSOFF and AMSOFF and BMSON and AMSON situations.

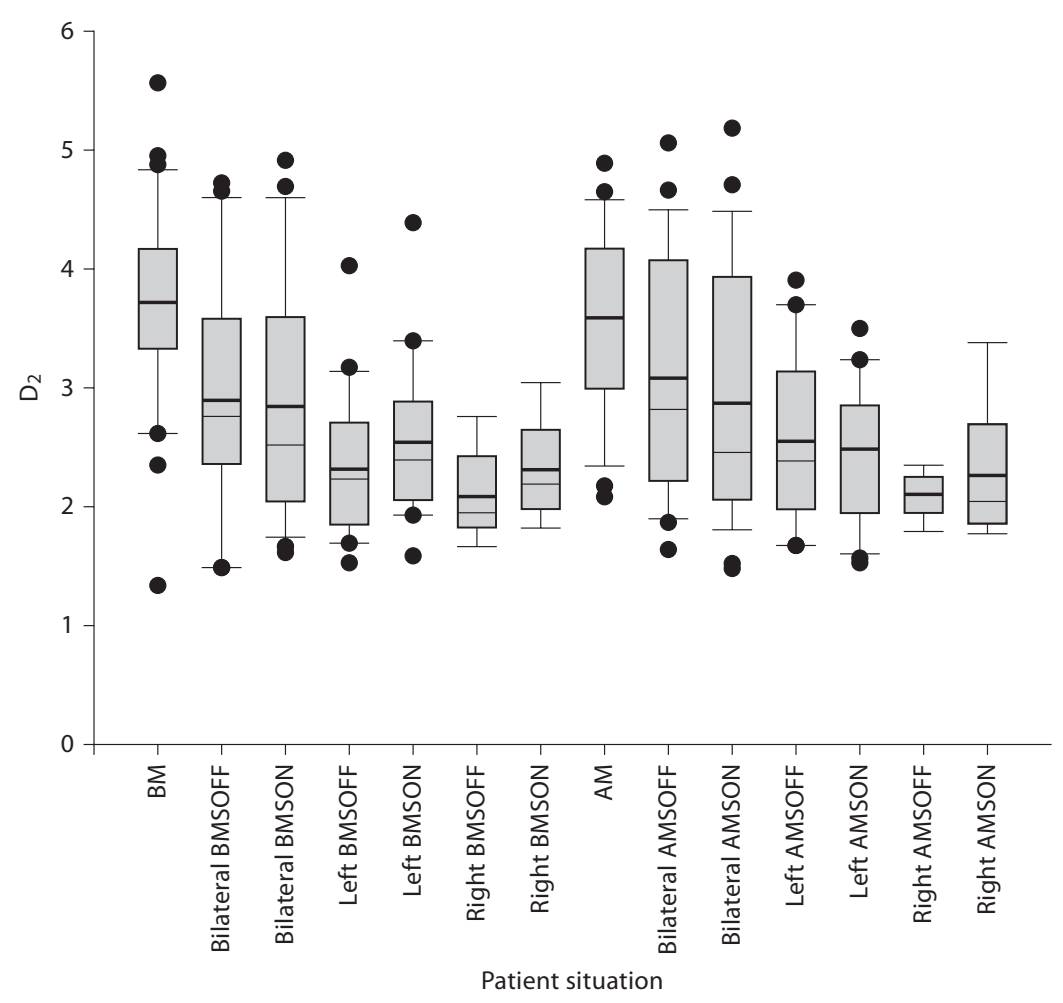

\section{Discussion}

The results of this study support the validity of nonlinear dynamic analysis as a clinical tool to evaluate the effects of DBS and levodopa on voice. Mean $\mathrm{ID}_{2}$, produced from nonlinear dynamic analysis, yielded significantly lower values in the bilateral, left, and right subsets of the DBS group than in the control group, indicating an improvement in PD voice. Statistically significant results from perturbation measures show similar trends to correlation dimension, lending credibility to the significant differences between the DBS and control group detected by correlation dimension. Mean $l v A m$ and $l v \mathrm{~F}_{0}$ mirrored the results of mean $\mathrm{ID}_{2}$, and mean lshimmer values were significantly lower for the bilateral DBS group, supporting an improvement in PD voice. Perturbation results that were not significant showed lower ljitter, lshimmer, $\mathrm{lvF}_{0}$, and $\operatorname{lvAm}$ values and higher SNR values for the DBS group, which agree with the results from nonlinear dynamic analysis.
Correlation dimension quantifies vocal irregularity, which may be caused by vocal fold stiffness in PD patients. Decreases in correlation dimension may indicate decreased vocal fold stiffness and more normal contractions of the vocal folds in PD patients, specifically of the antagonistic thyroarytenoid and cricothyroid muscles [23]. The discrepancy between the results from nonlinear dynamic and perturbation analysis may be due to the exclusion of aperiodic vocal samples from perturbation analysis. Previous studies have shown that perturbation analysis is unreliable for aperiodic vocal samples, which are commonly found in PD voice [20-25, 29].

The direct relationship between nonlinear dynamic and perceptual measures of voice is unclear. Correlation dimension quantifies aperiodic vocal patterns and therefore should reflect the perceptual characteristic of hoarseness [23]. In this study, although both perceptual and nonlinear dynamic results indicate improvement in PD voice with DBS, perceptual results show improvement in the stimulator-on condition as compared to the stimulator-off condition whereas nonlinear dynamic results 
Fig. 5. Boxplot of perceptual ratings of general vocal impairment for nonsurgical patients in the BM and AM situations and surgical patients (bilateral, left, and right) in the BMSOFF and AMSOFF and BMSON and AMSON situations.

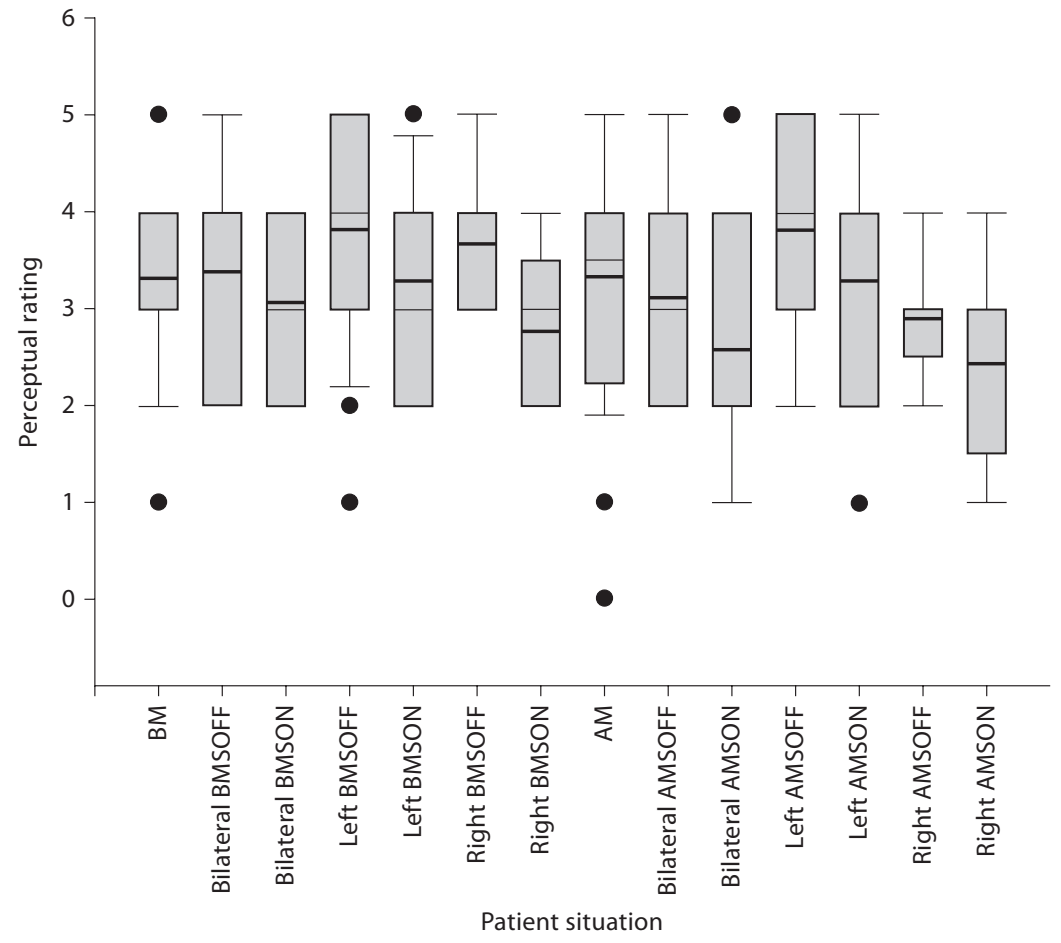

show improvement in the stimulator-on condition as compared to the no-surgery condition. Possible reasons for the discrepancy may include the use of a rating of general vocal impairment rather than of hoarseness and the small number of experienced raters. Nonlinear dynamic analysis is more time-effective and cost-effective than perceptual analysis and is the only objective method of analysis that exists for aperiodic voice. Given the unclear relationship between the two types of analysis, however, nonlinear dynamic analysis may only serve as a complement to perceptual analysis in the clinical setting. More rigorous studies are needed to elucidate the correlation between nonlinear dynamic and perceptual measures of Parkinsonian voice.

The conclusions of this study on the effectiveness of DBS and levodopa should be regarded with caution, as the purpose of this study was to evaluate the validity of nonlinear dynamic analysis as a clinical tool for detecting improvements in voice from DBS and levodopa treatment. The results indicate that DBS significantly improves voice with or without levodopa treatment and that levodopa treatment may not improve PD voice with or without DBS. Improvements in PD voice associated with levodopa have been shown to decline in the long run [10, $37,38]$. This decline in the effectiveness of levodopa may be attributed to an increase in nondopaminergic lesions outside of the basal ganglia or decreased dopamine transmission within the basal ganglia itself [15]. Patients in this study had Hoehn-Yahr scores of III or IV, indicating a more advanced stage of PD, and more severe vocal impairment as shown by the presence of subharmonics in their vocal waveform. Therefore, effectiveness of levodopa treatment may have already declined, perhaps from the increased prevalence of nondopaminergic lesions [4, $7,8,39-41]$. No interaction was found between levodopa and DBS treatment. Although two interaction terms were significant, the multiple comparisons did not generate any significant differences. All other interaction terms were not significant, indicating that low or high levels of levodopa were not correlated with either the stimulatoroff or stimulator-on conditions and may show a lack of synergistic effects between the two treatments. 
The conclusions of this study have several limitations. The absence of a true stimulator-off condition makes it difficult to pinpoint DBS as the source of the vocal improvement in the PD patients. In addition, the sample size is limited by the inclusion criteria of $\mathrm{PD}$ and qualification for DBS surgery. Furthermore, vocal characteristics, especially in patients with $\mathrm{PD}$, are highly variable from individual to individual. Although patients within the baseline and surgical groups were selected to be as consistent as possible, differences in the severity of PD as well as vocal machinery may have affected the results. Similar UPDRS-III item 18 scores, which specifically evaluate speech, however, may indicate that the two groups had similar initial levels of vocal impairment.

This study has applied nonlinear dynamic analysis to the evaluation of aperiodic PD voices with DBS and le- vodopa treatment. Correlation dimension values indicate improvements in the PD vocal regularity in patients receiving DBS, with neither an apparent added benefit of levodopa treatment nor interaction with levodopa, but these conclusions on treatment effects should be regarded with caution. This study provides support for the validity of nonlinear dynamic analysis as a complementary clinical evaluation tool for PD vocal treatments.

\section{Acknowledgments}

This study was supported by NSFC (Natural Science Foundation of China) Grant No. 30328029.

\section{References}

-1 Marsden CD: Parkinson's disease. J Neurol Neurosurg Psychiatry 1994;57:672-681.

2 Hanson DG, Gerratt BR, Ward PH: Cinegraphic observations of laryngeal function in Parkinson's disease. Laryngoscope 1984; 94:348-353

3 Ramig LA, Scherer RC, Titze IR, Ringel SP: Acoustic analysis of voices of patients with neurologic disease: rationale and preliminary data. Ann Otol Rhinol Laryngol 1988; 97:164-172.

-4 Wolfe VI, Garvin JS, Bacon M, Waldrop W: Speech changes in Parkinson's disease during treatment with L-dopa. J Commun Disord 1975;8:271-279.

5 Critchley EM: Speech disorders of Parkinsonism: a review. J Neurol Neurosurg Psychiatry 1981;44:751-758.

-6 Gentil M, Garcia-Ruiz P, Pollak P, Benabid AL: Effect of stimulation of the subthalamic nucleus on oral control of patients with Parkinsonism. J Neurol Neurosurg Psychiatry 1999;67:329-333.

7 Sanabria J, Ruiz PG, Gutierrrez R, Marquez F, Escobar P, Gentil M, Cenjor C: The effect of levodopa on vocal function in Parkinson's disease. Clin Neuropharmacol 2001;24:99102.

8 De Letter M, Santens P, Van Borsel JV: The effects of levodopa on word intelligibility in Parkinson's disease. J Commun Disord 2005; 38:187-196.

9 Goberman AM: Correlation between acoustic speech characteristics and nonspeech motor performance in Parkinson disease. Med Sci Monit 2005;11:109-116.

10 Broggi G, Franzini A, Marras C, Romito L, Albanese A: Surgery of Parkinson's disease: inclusion criteria and follow-up. Neurol Sci 2003;24(suppl 1):S38-S40.
11 Hoffman-Ruddy B, Schulz G, Vitek J, Evatt M: A preliminary study of the effects of subthalamic nucleus (STN) deep brain stimulation (DBS) on voice and speech characteristics in Parkinson's Disease (PD). Clin Linguist Phon 2001;15:97-101.

12 Krack P, Batir A, Van Blercom N, Chabardes $S$, et al: Five-year follow-up of bilateral stimulation of the subthalamic nucleus in advanced Parkinson's disease. New Engl J Med 2003;349:1925-1934.

13 Kumar R, Lozano AM, Sime E, Lang AE: Long-term follow-up of thalamic deep brain stimulation for essential and parkinsonian tremor. Neurology 2003;61:1601-1604.

14 Vaillancourt D, Prodoehl J, Metman LV, Bakay RA, Corcos DM: Effects of deep brain stimulation and medication on bradykinesia and muscle activation in Parkinson's disease. Brain 2004;127:491-504.

15 Bejjani BP, Gervais D, Arnulf I, Papadopoulos S, Demeret S, Bonnet AM, Cornu P, Damier P, Agrid Y: Axial parkinsonian symptoms can be improved: the role of levodopa and bilateral subthalamic stimulation. J Neurol Neurosurg Psychiatry 2000;68:595600.

-16 Sailer A, Cunic DI, Paradiso GO, Gunraj CA Wagle-Shukla A, Moro E, Lozano AM, Lang $\mathrm{AE}$, Chen R: Subthalamic nucleus stimulation modulates afferent inhibition in Parkinson disease. Neurology 2007;68:356-363.

17 Stefani A, Lozano A, Peppe A, Stanzione P, Galati S, Tropepi D, Pierantozzi M, Brusa L, Scarnati E, Mazzone P: Bilateral deep brain stimulation of the pedunculopontine and subthalamic nuclei in severe Parkinson's disease. Brain 2007;130:1596-1607.
18 Dromey C, Kumar R, Lang A, Lozano A: An investigation of the effects of subthalamic nucleus stimulation on acoustic measures of voice. Mov Disord 2000;15:1132-1138.

19 Gentil M, Chauvin P, Pinto S, Pollak P, Benabid AL: Effect of bilateral stimulation of the subthalamic nucleus on parkinsonian voice. Brain Lang 2001;78:233-240.

20 Hertrich I, Ackerman H: Gender-specific vocal dysfunctions in Parkinson's disease: electroglottographic and acoustic analyses. Ann Otol Rhinol Laryngol 1995;104:197202.

-21 Zhang Y, McGilligan C, Zhou L, Vig M, Jiang $\mathrm{J}$ : Nonlinear dynamic analysis of voices before and after surgical excision of vocal polyps. J Acoust Soc Am 2004;115:2270-2277.

22 Titze IR, Baken R, Herzel H: Evidence of chaos in vocal fold vibration; in Titze IR (ed): Vocal Fold Physiology: Frontiers in Basic Science. San Diego, Singular, 1993, pp 143188.

23 Rahn DA, Chou M, Zhang Y, Jiang J: Phonatory impairment in Parkinson's disease: evidence from nonlinear dynamic analysis and perturbation analysis. J Voice 2007;21:6471.

24 Herzel H, Berry D, Titze IR, Saleh M: Analysis of vocal disorders with methods from nonlinear dynamic analysis. J Speech Lang Hear Res 1994;37:1008.

25 Zhang Y, Jiang JJ: Nonlinear dynamic analysis in signal typing of pathological human voices. Electron Lett 2003;39:1021-1023.

26 Yu Z, Jiang J, Rahn DA: Studying vocal vibrations in Parkinson's disease with a nonlinear model. Chaos 2005;15:1-9.

$\checkmark 27$ Benabid AL: Deep brain stimulation for Parkinson's disease. Curr Opin Neurobiol 2003; 13:696-706. 
28 Milenkovic P, Read C: CSpeech Version 4 User's Manual. Madison, University of Wisconsin, 1992.

29 Titze IR: Workshop on Acoustic Voice Analysis: Summary Statement. Iowa City, National Center for Voice and Speech, 1995.

- 30 Grassberger P, Procaccia I: Measuring the strangeness of strange attractors. Physica D 1983;9:189-208.

-31 Narayanan SS, Alwan AA: A nonlinear dynamical systems analysis of fricative consonants. J Acoust Soc Am 1995;97:2511-2524.

- 32 Kumar A, Mullick SK: Nonlinear dynamical analysis of speech. J Acoust Soc Am 1996; 100:615-629.
33 Jiang JJ, Zhang Y, Ford CN: Nonlinear dynamics of phonations in excised larynx experiments. J Acoust Soc Am 2003;114:21982205.

34 Jiang JJ, Zhang Y, McGilligan C: Chaos in voice, from modeling to measurement. Voice 2006;20:2-17.

35 Zhang Y, Jiang JJ, Biazzo L, Jorgensen M: Perturbation and nonlinear dynamic analyses of voices from patients with unilateral laryngeal paralysis. J Voice 2005; 19:519-528.

36 Santens P, De Letter M, Van Borsel J, De Reuck J, Caemaert J: Lateralized effects of subthalamic nucleus stimulation on different aspects of speech in Parkinson's disease. Brain Lang 2003;87:253-358.

-37 The Deep-Brain Stimulation for Parkinson's Disease Study Group: Deep-brain stimulation of the subthalamic nucleus or the pars interna of the globus pallidus in Parkinson's disease. N Engl J Med 2001;345:956-963.
38 Pinto S, Gentil M, Fraix V, Benabid A, Pollak P: Bilateral subthalamic stimulation effects on oral force control in Parkinson's disease. J Neurol 2003;250:179-187.

-39 Goberman AM, Blomgren M: Parkinsonian speech disfluencies: effects of L-dopa-related fluctuations. J Fluency Disord 2003;28:5570.

40 Poluha PC, Teulings HL, Brookshire RH: Handwriting and speech changes across the levodopa cycle in Parkinson's disease. Acta Psychol (Amst) 1998;100:71-84.

41 Jiang J, Lin E, Wang J, Hanson DG: Glottographic measures before and after levodopa treatment in Parkinson's disease. Laryngoscope 1999;109:1287-1294. 